\title{
SISTEM INFORMASI DOSEN UNIKS ONLINE
}

\author{
Harianja \\ Fakultas Teknik, Universitas Islam Kuantan Singingi \\ Jl. Gatot Subroto KM. 7 Jake Telukkuantan Riau \\ Email : harianja@uniks.ac.id
}

\begin{abstract}
Uniks sebagai salah satu perguruan tinggi di Indonesia memiliki lebih kurang seratus dosen tetap atau tenaga pendidik. Tenaga Pendidik ini merupakan ujung tombak pelaksana catur darma Uniks dan juga menjadi tolok ukur masyarakat dalam menilai kinerja Uniks. Sebagai tolok ukur, tentunya Uniks harus mempublikasikan kegiatan caturdarma yang dilakukan dosennya. Kenyataan yang terjadi saat ini masyarakat tidak banyak mengetahui dosen Uniks dan kegiatan caturdarma yang sudah dilakukannya. Penelitian ini bertujuan untuk merancang sistem informasi dosen Uniks dengan harapan dapat dijadikan sarana untuk mempublikasikan dosen dan kegiatan caturdarma yang dilakukannya.
\end{abstract}

Kata kunci: sistem informasi, dosen Uniks, online

\begin{abstract}
Uniks is one of institute in Indonesia has around one hundred lecturers or educators. The educator is the pioneer in the university to do caturdharma Uniks and become measurement in assessment the performance of Uniks. Certainly, Uniks have to publish caturdharma activities from the lecturers, cause the society still unknown about the caturdharma activities. The aim of this research is to built the informations system of Uniks' lecturers to publish all of the caturdharma activities.
\end{abstract}

Keyword: information system, Uniks, lecturer, online

\section{PENDAHULUAN}

Uniks sebagai salah satu institusi pendidikan, mempunyai tenaga pendidik (dosen) yang akan membantu fungsi Uniks sebagai pelaksana Tri dharma perguruan tinggi. Dosen ini merupakan tulang punggung bagi terlaksananya institusi perguruan tinggi. Sebagai tulang punggung, tentunya dosen selalu menjadi acuan bagi masyarakat untuk mengetahui dan mengukur keberadaan perguruan tinggi tersebut. Bahkan kecenderungan di masyarakat, baik buruknya perguruan tinggi mereka nilai dari kualitas, kuantitas dan kinerja para dosennya dalam melaksanakan fungsi tri dharma. Akibatnya banyak perguruan tinggi yang menjadikan kualitas, kuantitas dan kinerja dosen sebagai ajang promosi dan pengenalan institusinya, baik sebagai sarana untuk penarik minat maupun menaikkan reputasinya di tengah masyarakat. Namun saat ini tidak banyak masyarakat yang mengetahui kiprah, kualitas, kuantitas dan kinerja dosen Uniks dan sampai saat ini Uniks juga belum mempunyai sarana khusus untuk mempublikasikan tentang dosen yang dimilikinya. Berdasarkan alasan tersebut kami bermaksud untuk membangun sebuah sistem informasi yang dapat dijadikan Uniks untuk mempublikasikan dosen-dosennya beserta seluruh aktivitas akademik dan non akademiknya. 
$\mathrm{Hal}: 23-32$

Dari uraian latar belakang di atas, maka dapat dibuat rumusan masalahnya. Bagaimana membangun sistem informasi dosen Uniks agar dapat disajikan secara online. Adapun tujuan dari penelitian ini sebagai berikut :

1. Membuat Sebuah sistem informasi dosen Uniks yang disajikan secara online

2. Memberikan motivasi kepada dosen Uniks untuk memanfaatkan teknologi informasi dalam usaha mengembangkan, menginformasikan perkembangan karirnya sebagai dosen.

3. Membuat sarana alternatif yang dapat dijadikan Uniks untuk mempublikasikan dosendosennya.

\section{Manfaat Penelitian (Luaran)}

1. Dihasilkannya sistem informasi dosen Uniks secara online

2. Mudah mengetahui perkembangan karir dosen Uniks

3. Dapat dijadikan tempat publikasi kegiatan dosen Uniks

\section{Metode Penelitian}

Penelitian ini diawali dengan mengidentifikasi dan merumuskan masalah yang akan dijadikan objek penelitian, menentukan tujuan penelitian. Setelah itu dilanjutkan dengan studi literatur tentang masalah-masalah yang berkaitan dengan objek penelitian. Kemudian dilanjutkan dengan perancangan dan pembuatan sistem, pengujian atau evaluasi terhadap sistem. Jika sistem sudah bagus dilanjutkan dengan implementasi dan penulisan laporan. Berikut ini merupakan kerangka kerja dari penelitian ini.

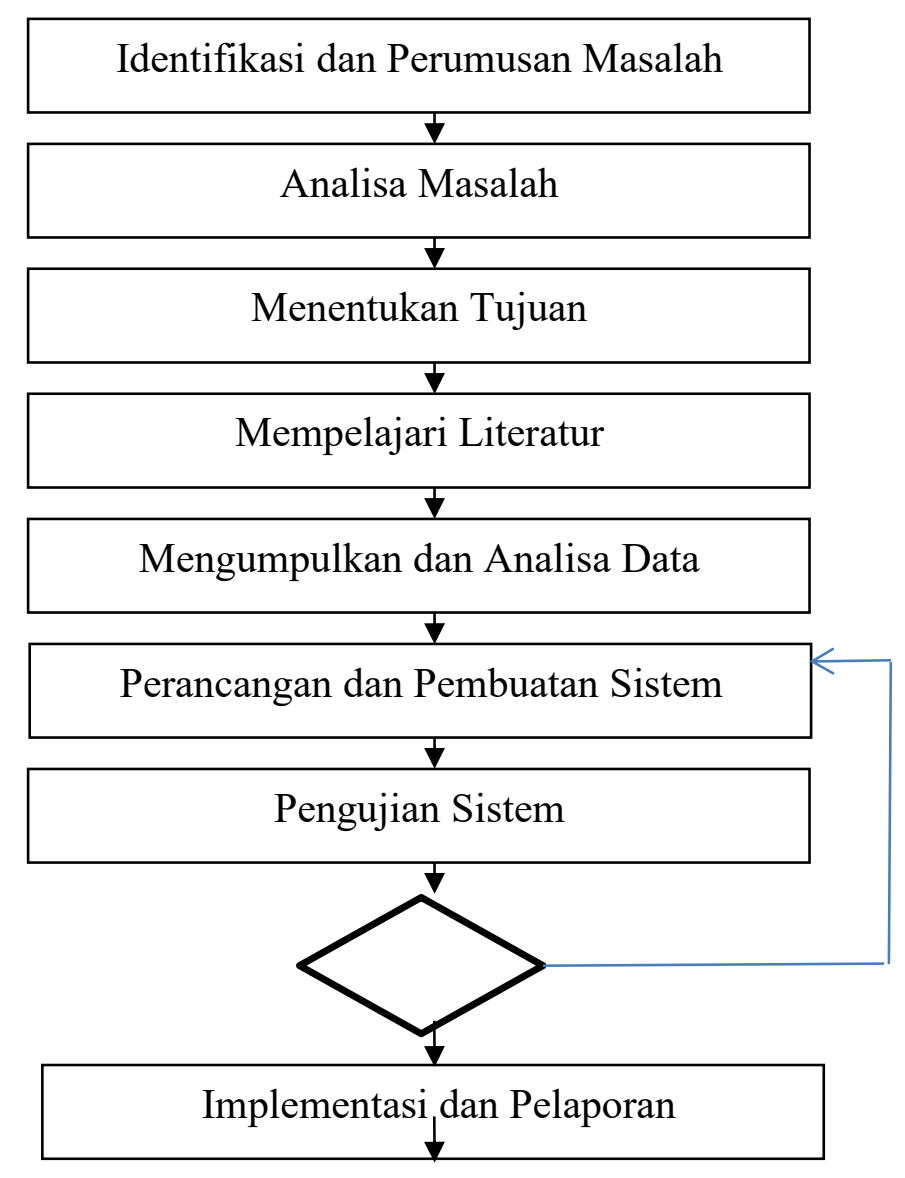

Gambar 2.1 Kerangka Kerja Penelitian 
$\mathrm{Hal}: 23-32$

Dari kerangka kerja yang digambarkan di atas maka dapat diuraikan pembahasan masing-masing kegiatan sebagai berikut :

1. Identifikasi dan perumusan masalah

Pada tahap ini dilakukan pengidentifikasian terhadap masalah yang akan diteliti, kemudian dilanjutkan dengan proses perumusan masalah yang akan dijadikan dasar untuk penyelesaian penelitian ini.

2. Analisa masalah

Merupakan tahapan untuk menspesifikkan masalah yang menjadi topik dalam penelitian ini. Melakukan analisis lebih lanjut terhadap masalah yang dikaji serta batasan-batasan terhadap masalah tersebut dan analisis terhadap sistem yang ada.

3. Menentukan tujuan

Berdasarkan identifikasi dan perumusan masalah yang telah ada pada tahap sebelumnya, dirumuskan tujuan penelitian yang nantinya berguna untuk memperjelas tentang apa saja yang menjadi sasaran dari penelitian ini.

4. Mempelajari literatur

Studi literatur dilakukan untuk mengetahui metode apa yang akan digunakan untuk menyelesaikan permasalahan serta mendapatkan dasar-dasar referensi yang kuat bagi peneliti dalam menerapkan suatu metode yang digunakan.

5. Mengumpulkan data dan analisa

Merupakan pengumpulan data penunjang yang dapat membantu pelaksanaan penelitian ini. Data penunjang tersebut dapat berupa data dosen, fakultas dan prodi, kegiatan dosen, materi kuliah, penelitian, pengabdian, jurnal dan karya tulis, dan datadata lain yang dibutuhkan untuk penyelesaian penelitian ini.

6. Perancangan dan Pembuatan sistem

Setelah dilakukan studi literatur, pengumpulan data maka dilanjutkan dengan proses perancangan dan pembuatan sistem.

7. Pengujian sistem

Merupakan tahapan proses ujicoba terhadap sistem yang sudah dibuat. Pada tahap ini akan diketahui apakah sistem sudah sesuai dengan tujuan penelitian atau belum. Jika sistem sudah sesuai maka akan dilanjutkan dengan tahap implementasi dan pelaporan atau pendokumentasian penelitan. Jika belum sesuai akan dilakukan kembali analisa dan perancangan terhadap sistem sampai sistem dianggap sesuai.

8. Implementasi dan pelaporan

Merupakan proses penerapan aplikasi yang dirancang untuk digunakan di kampus Uniks dan penulisan laporan terhadap hasil penelitian yang telah dilakukan. 


\section{Hasil dan Pembahasan}

\section{Login Admin}

Sistem yang dibangun ini dibagi menjadi dua sisi yaitu sisi admin dan sisi user. Sisi admin dapat digunakan untuk melakukan pengeditan atau pengolahan semua data yang ada dalam sistem informasi dosen Uniks online. Sisi user atau pengguna merupakan bagian yang akan dilihat oleh siapa saja yang melihat alamat situs sistem informasi dosen Uniks tersebut. Kedua sisi ini dapat digambarkan dengan use case diagram seperti gambar berikut.

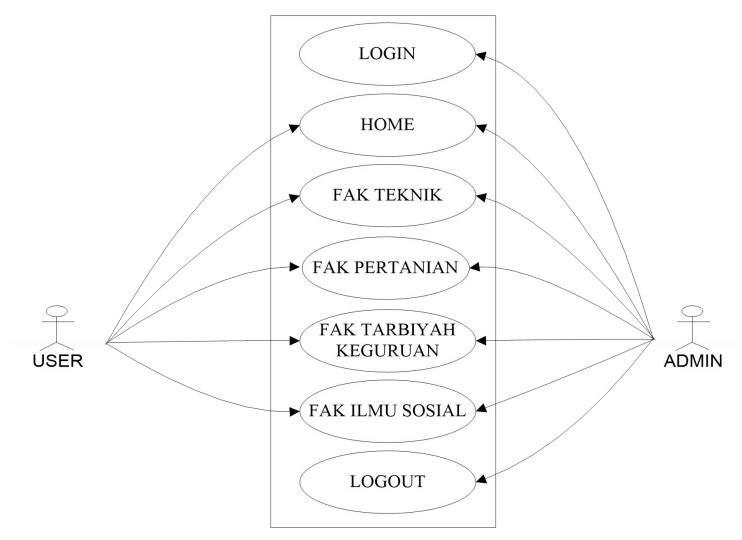

\section{Gambar 4.1. Use Case Diagram}

Pada gambar di atas terlihat bahwa User tidak diberi hak untuk mengubah data - data situs, tetapi mereka diberikan izin untuk melihat seluruh menu yang tersedia di sistem. Agar user dapat masuk ke halaman sistem, pengguna cukup menuliskan alamat situs "www.dosen.uniks.ac.id" di web browser seperti monzila, internet explorer dan lain-lain. Selain itu user juga dapat membuka situs dosen.uniks.ac.id melalui link yang sudah disediakan di situs "www.uniks.ac..id". Dari gambar terlihat perbedaan hak antara admin dan user. Admin berhak atau dapat mengakses semua fasilitas situs sedangkan user hanya bisa melihat semua isi situs yang terdapat pada menu sistem. Untuk masuk ke halaman admin, pemilik harus masuk ke situs terlebih dahulu melalui login admin.

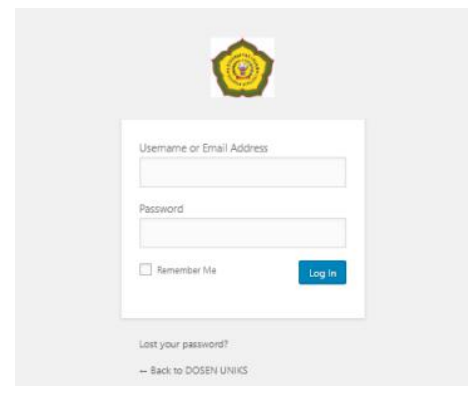

\section{Gambar 4.2. Tampilan Halaman Login Admin}

Kemudian masukkan nama penguna atau alamat email dan kata sandi, kemudian dilanjutkan dengan mengklik log in. 
Hal : $23-32$

\section{Tampilan Output}

Output sistem merupakan tampilan keluaran yang akan dilihat oleh user terhadap sistem yang dibuat. Berikut ini adalah diantara output sistem yang dapat dilihat oleh user

\section{Tampilan Halaman Beranda (Home Page)}

Pada halaman beranda, user dapat melihat semua hasil postingan dan menu yang terdapat pada situs. Halaman beranda ini merupakan halaman dinamis sehingga setiap postingan akan dimunculkan sesuai dengan urutan tanggal dikeluarkannya postingan. Pada halaman ini juga terdapat beberapa menu yang mencakup semua fakultas yang ada di Uniks yaitu Fakultas Teknik, Fakultas Pertanian, Fakultas Tarbiyah dan Keguruan, Fakultas Ilmu Sosial.

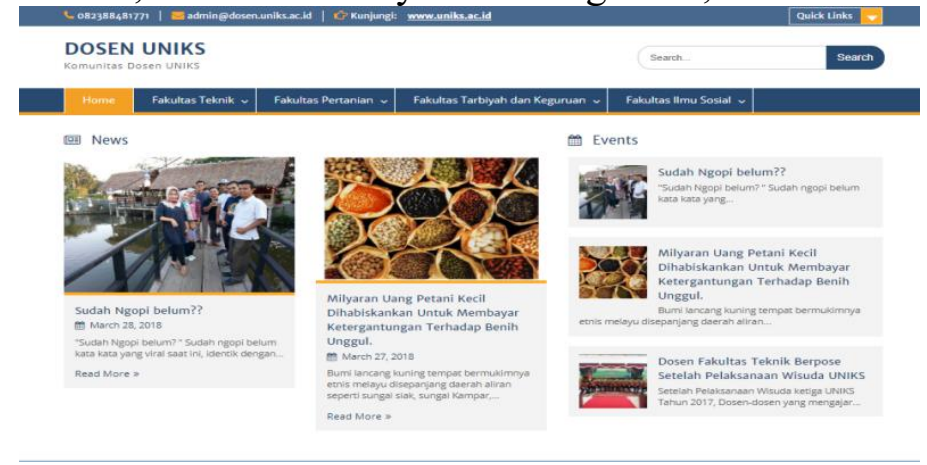

\section{Gambar 4.3. Tampilan halaman Home (Beranda)}

\section{Halaman Menu Fakultas}

Jika kita menempatkan pointer pada menu fakultas, maka akan muncul submenu berupa prodi yang ada pada masing fakultas. Jika kita mengklik menu fakultas akan muncul halaman fakultas yang merupakan gambaran tentang fakultas yang dipilih.

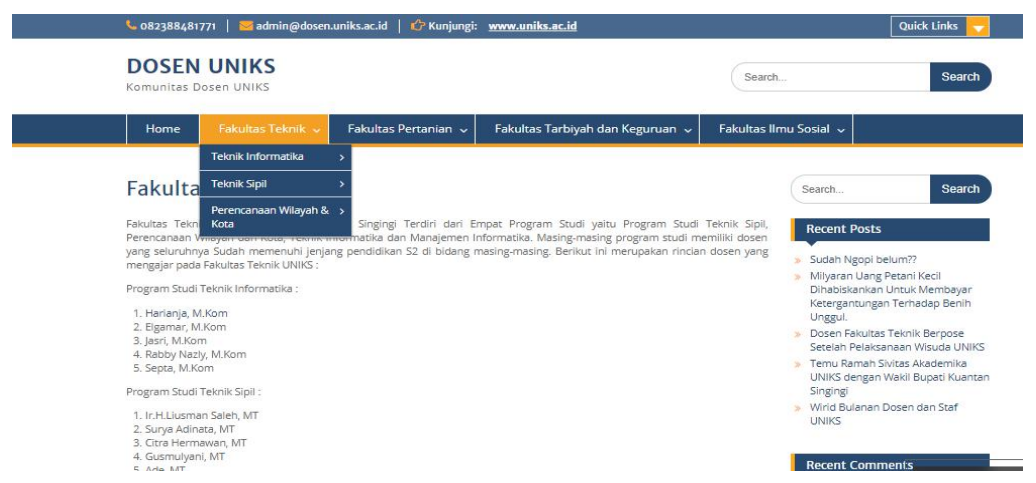

Gambar 4.4. Tampilan Halaman Menu Fakultas

\section{Tampilan Submenu Prodi}

Jika kita menempatkan pointer pada sub menu prodi, maka akan muncul sub sub menu yang isinya merupakan link situs dosen - dosen yang berada pada prodi yang bersangkutan 
Hal : $23-32$

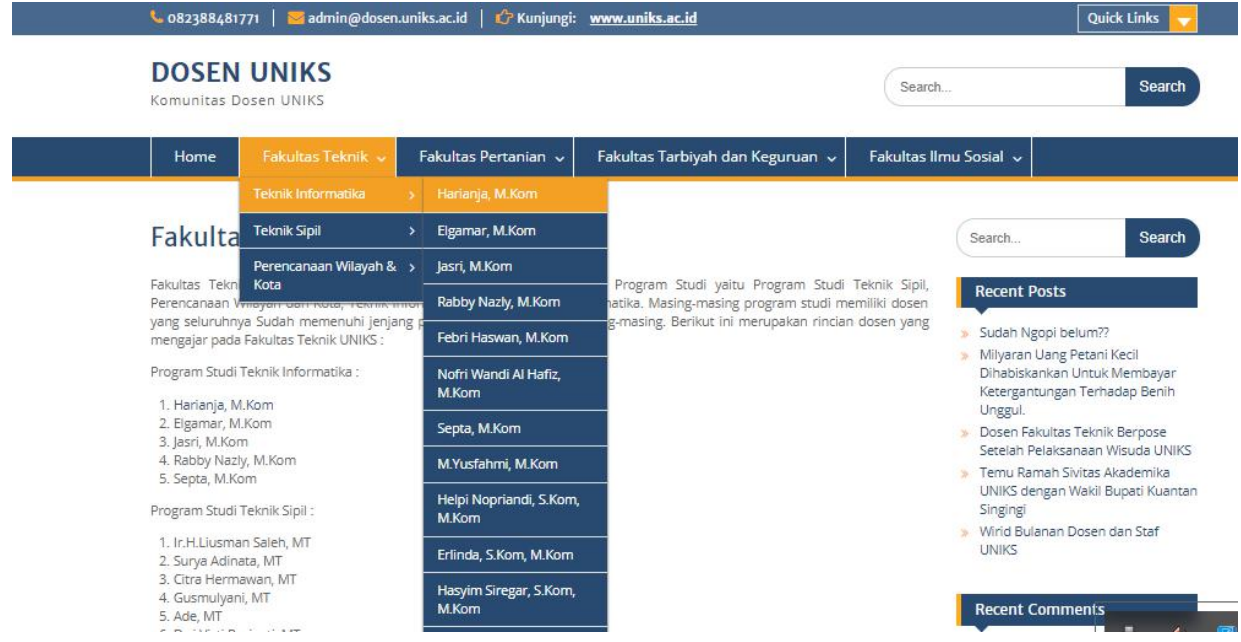

Gambar 4.5. Tampilan Sub Menu Prodi

Halaman Web Dosen

Untuk melihat halaman dosen, kita dapat mengklik sub menu yang terdapat pada submenu prodi. Ketika sub menu dosen diklik maka akan muncul halaman web dosen seperti tampilan gambar berikut.

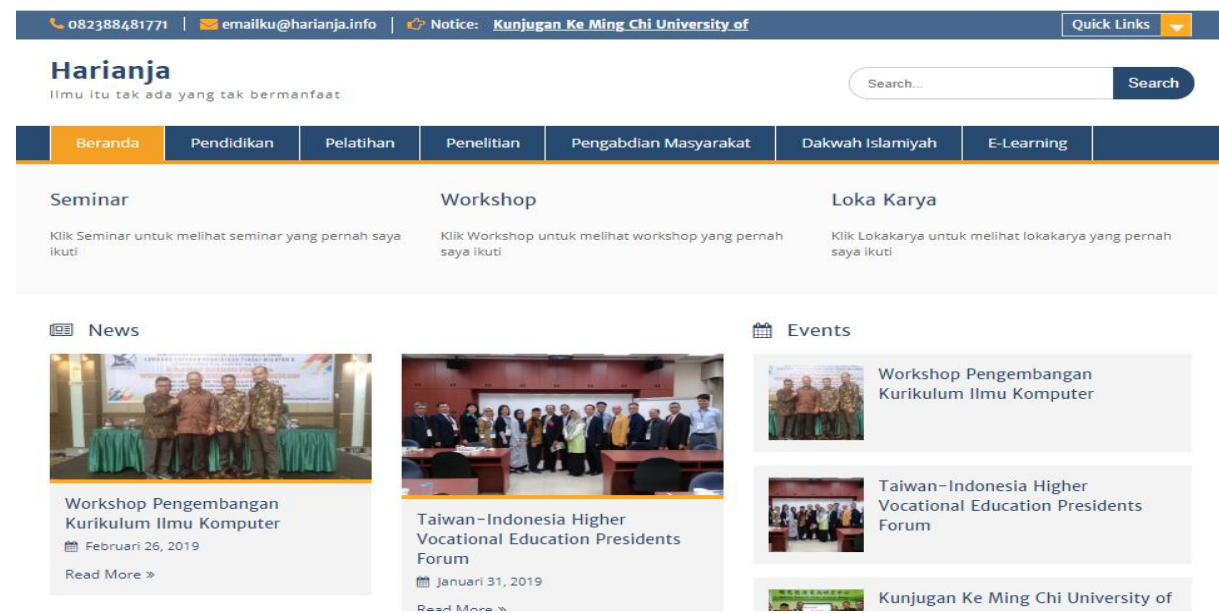

Gambar 4.6. Tampilan Halaman Web Dosen

Pada halaman web dosen terdapat beberapa menu yang mencakup pelaksanaan chaturdharma dosen seperti : pendidikan, pelatihan, penelitian, pengabdian masyarakat, dakwah Islamiyah dan e-learning. Selain itu pada halaman utama web dosen juga tersedia link untuk melihat seminar, workshop dan lokakarya yang pernah diikuti dosen. Jika menu pendidikan diklik maka user akan melihat halaman mata kuliah yang diajar oleh dosen yang bersangkutan (riwayat mengajar dosen tiap semester). 
Hal : $23-32$

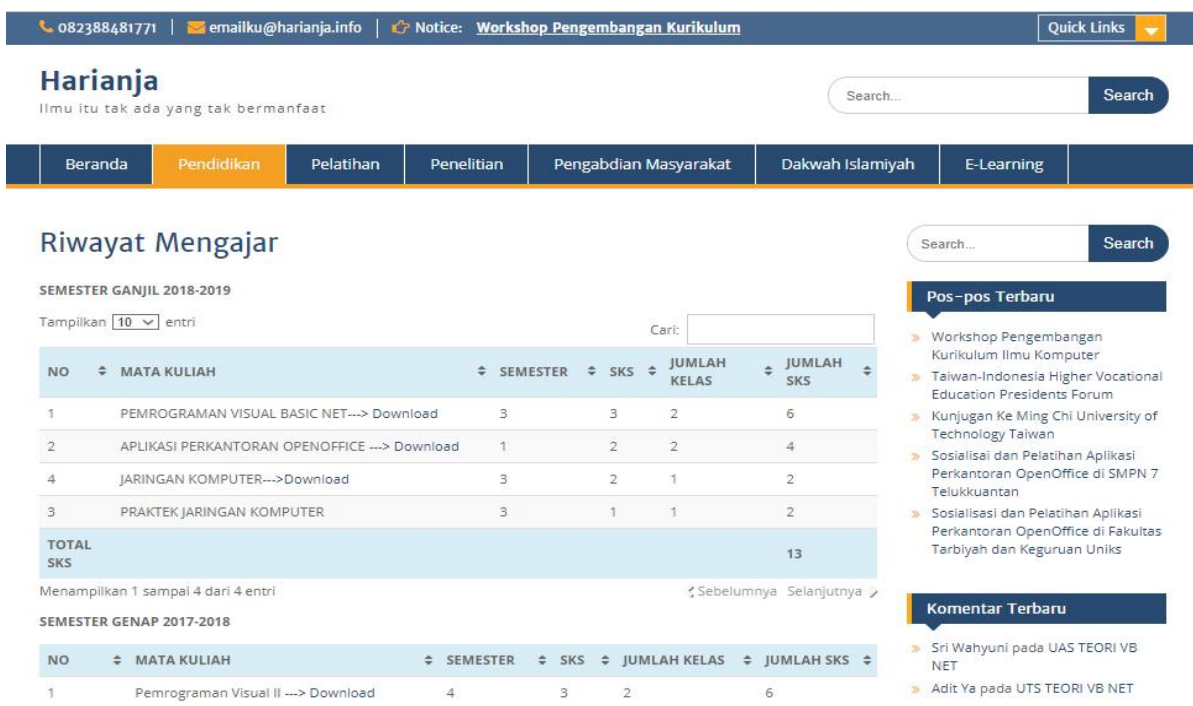

Gambar 4.7. Tampilan Halaman Riwayat Mengajar Dosen

Jika link matakuliah di klik akan muncul halaman mata kuliah yang diajarkan dosen (kedepannya bisa dikembangkan menjadi e-learning dosen ) seperti gambar berikut

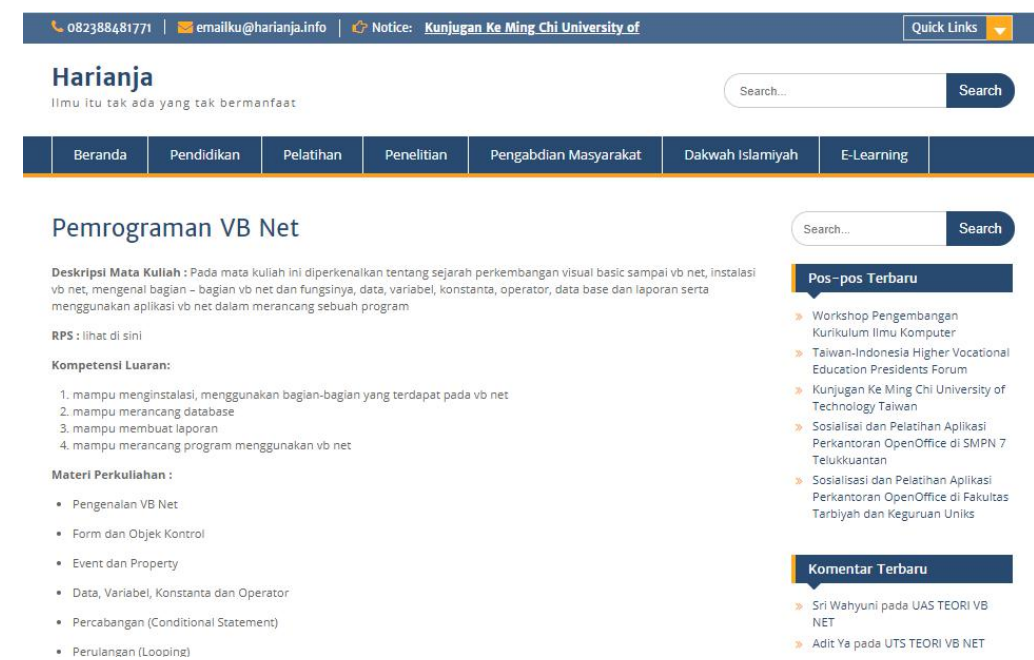

Gambar 4.8. Tampilan Halaman Mata Kuliah

Menu Penelitian

Menu ini dapat digunakan user untuk melihat riwayat penelitian yang telah dilakukan oleh dosen yang bersangkutan baik penelitian internal maupun penelitian eksternal.

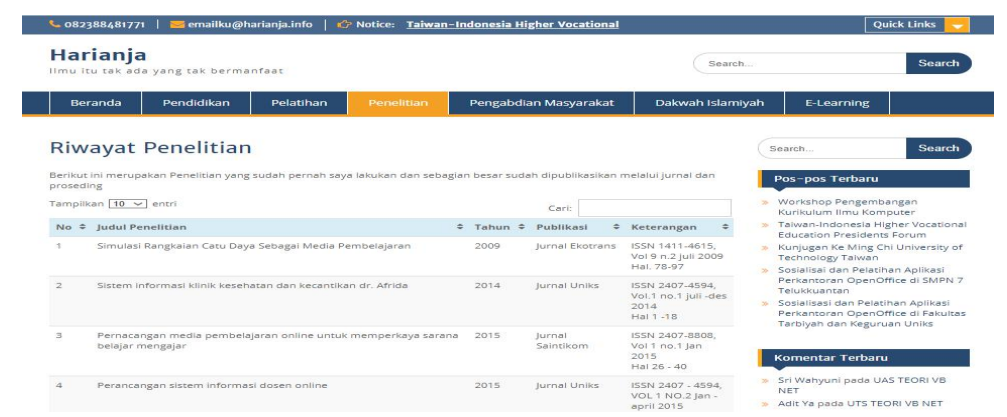

Gambar 4.9. Tampilan Halaman Penelitian 
Hal : $23-32$

Menu Pelatihan

Menu ini dapat digunakan user untuk melihat riwayat pelatihan yang telah diikuti oleh dosen yang bersangkutan.

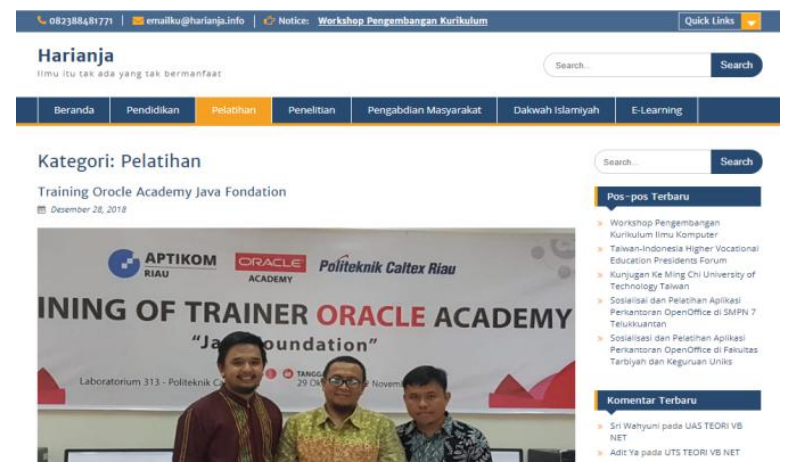

\section{Gambar 4.10. Tampilan Halaman Menu Pelatihan}

Menu Pengabdian Masyarakat

Pada Pengabdian Masyarakat user dapat melihat pengabdian apa saja yang telah dilakukan oleh dosen yang bersangkutan. Halaman ini bisa diisi dengan foto pengabdian, SK, Laporan dan lain sebagainya yang, sehingga setiap kegiatan pengabdian dapat dilakukan pengarsipan secara online

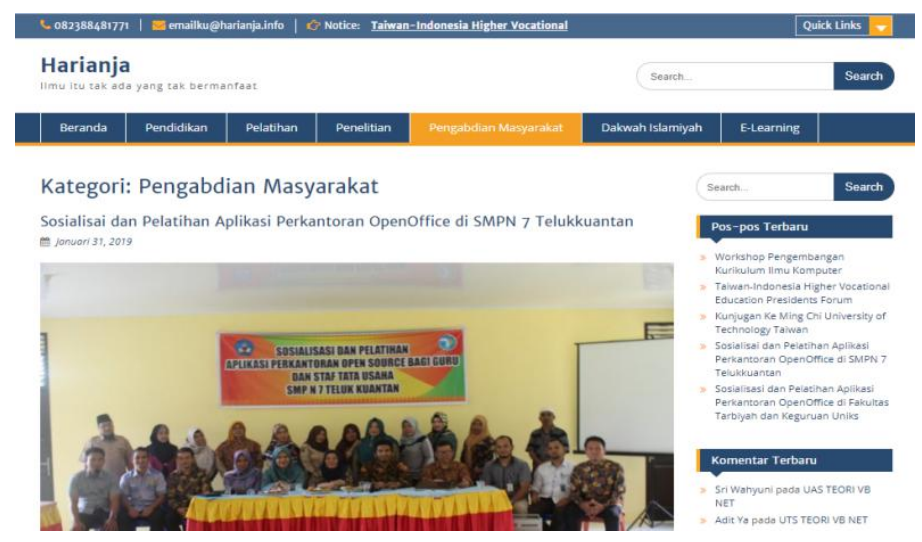

\section{Gambar 4.11. Tampilan Halaman Pengabdian Masyarakat}

Menu Seminar

Pada bagian ini user dapat melihat seminar apa saja yang telah diikuti oleh dosen yang bersangkutan. 
Hal : $23-32$

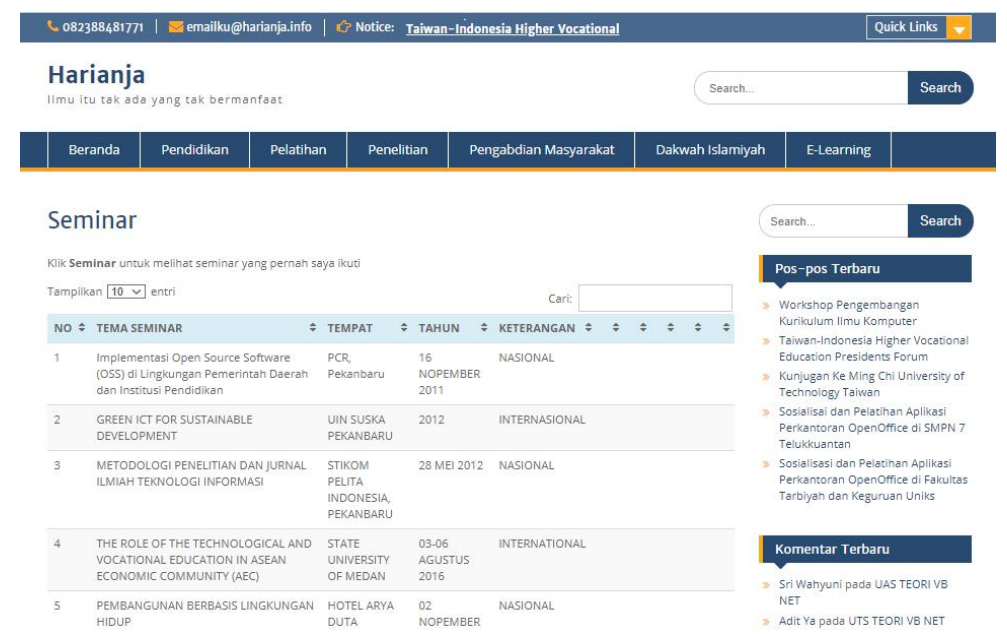

Gambar 4.12. Tampilan Halaman Seminar

Menu Workshop

Pada bagian ini user dapat melihat Workshop yang sudah pernah diikuti oleh dosen yang bersangkutan.

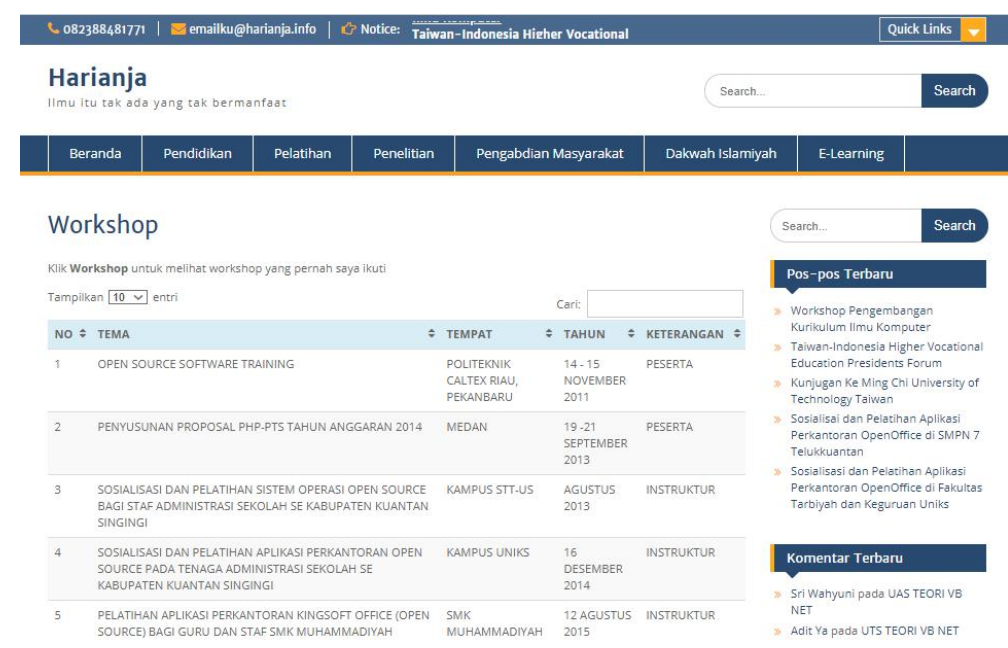

Gambar 4.13. Tampilan Halaman Workshop

\section{Pembahasan}

Pada penelitian ini penulis mencoba untuk menampilkan seluruh fakultas dan prodi yang ada di Uniks, kemudian pada masing - masing prodi disediakan submenu nama - nama dosen yang ada pada prodi yang dipilih. Jika menu fakultas yang dipilih, maka akan muncul halaman fakultas dimana pada halaman ini akan tampak deskripsi tentang fakultas berikut prodi dan dosen yang dimilikinya. Jika yang dipilih dosen makan kita akan dibawa ke halaman atau situs dosen dimana pada bagian ini akan terlihat seluruh aktifitas dosen yang bersangkutan terutama yang berkaitan dengan tugasnya sebagai pelakasana caturdharma Uniks. Pada bagian beranda akan terlihat semua postingan yang berkaitan dengan kegiatan dosen secara kolektif, sedangkan pada bagian menu nama dosen akan terlihat aktifitas dosen secara individu. 


\section{Kesimpulan}

Setelah melihat hasil dan pembahasan maka dapat disimpulkan bahwa sistem informasi dosen Uniks online ini sangat bagus dijadikan sebagai media informasi dosen-dosen Uniks secara online, karena dengan sistem ini mahasiswa, rekan sejawat, Peguruan tinggi, yayasan dan masyarakat dapat dengan mudah mengetahui informasi tentang dosen Uniks dan aktivitasnya yang berkaitan dengan pelaksanaan chatur dharma. Sistem informasi ini dapat juga dikembangkan menjadi media pembelajaran online, dan juga dapat dijadikan tempat pengarsipan secara online, sehingga saat dibutuhkan dosen dapat mendownload file yang telah disimpan di sistemnya.

\section{Daftar Pustaka}

Abdul Kadir, 2003. "Pengenalan Sistem Informasi”, Penerbit : Andi Offset Yogyakarta Alexander F.K. Sibero, 2011. “Kitab Suci Web Programming” MediaKom Yogyakarta

Ali Zainal, 2011. "Cepat dan Mudah Membuat Website Keren dengan Wordpress 3.x”, Media Kita Jakarta.

Apri Junaidi, 2010. "Modul Pembelajaran Wordpress dan Joomla". Penerbit Modula Bandung.

Bunafit Nugroho. 2004. "Aplikasi Pemrograman Web Dinamis dengan PHP dan MySQL". Yogyakarta : Gava Media.

Harianja, 2014. "Perancangan Media Belajar Online Untuk Memperkaya Media Pembelajaran", Jurnal UNIKS

I Dewa Made Adi Baskara Joni, I Kadek Budi Sandika, 2016. "Sistem Informasi Manajemen Sebagai Alat Pengelolaan Penelitian Dosen", Jurnal Lontar Komputer, Vol. 7 No. 1

Jogiyanti, HM. 2002. “Sistem Informasi Manajemen”. Yogyakarta : Andi.

Lina Rahmawati, 2012. "Perancangan Website sebagai sarana promosi pada MTs Ma'arif Nu 1 Ajibarang”, Jurnal Telematika Vol. 5 No. 2

Ni Wayan Sumartini Saraswati, Eddy Hartono, 2017. "Sistem Pengolahan Data Dosen Tetap STMIK STIKOM Indonesia Berbasis Website", Jurnal Teknologi informasi dan Komputer, Vol 3 No. 1

Syamsiah Siti. 2009. "Mengenal Pemrograman HTML Sebagai Dasar Pembuatan Web". Yogyakarta : Bina Sarana.

Syarifah Putri Agustini Alkadri, 2017. "Rancang Bangun Sistem Informasi Evaluasi Dosen Universitas Muhammadiyah". Junal Cybernetics Vol. 01 No. 02 